\title{
Flutuações mensais na abundância dos Charadriidae e Scolopacidae da praia da Ilha Comprida, São Paulo, Brasil
}

\author{
Edison Barbieri ${ }^{1,4}$, Roberta Tonolli Chiavone Delchiaro ${ }^{2}$ \& Joaquim Olinto Branco ${ }^{3}$ \\ ${ }^{1}$ Instituto de Pesca - APTA, Secretária da Agricultura e Abastecimento do Estado de São Paulo - SAA, \\ CP 61, CEP 11990-000, Cananéia, SP, Brasil \\ ${ }^{2}$ Programa de Pós-graduação em Oceanografia, Instituto Oceanográfico, \\ Universidade de São Paulo - USP, CEP 05508-120, São Paulo, SP, Brasil \\ ${ }^{3}$ Centro de Ciências Tecnológicas, da Terra e do Mar - CTTMar, Universidade do Vale - UNIVALI, \\ CP 360, CEP 88301-970, Itajai, SC, Brasil \\ ${ }^{4}$ Autor para correspondência: Edison Barbieri, e-mail: edisonbarbieri@yahoo.com.br
}

BARBIERI, E., DELCHIARO, R.T.C. \& BRANCO, J.O. Monthly fluctuation in the abundance of Scolopacidae and Charadriidae at Ilha Comprida beach, SP, Brazil. Biota Neotrop. 13(3): http://www.biotaneotropica.org. br/v13n3/en/abstract?inventory+bn02013032013

\begin{abstract}
We recorded the frequency of occurrence and monthly fluctuations of Charadriidae and Scolopacidae along a 70km transect of beach between Boqueirão Sul and Boqueirão Norte north of Comprida island, São Paulo State over a 1-year period (Jan - 2010 to Dec - 2010). A total of 12.153 shorebirds were recorded. The greatest abundance occurred between October and April and the lowest occurred between May and September. The most abundant of the 20 species recorded were Charadrius semipalmatus, Charadrius colaris, Vanellus chilensis and Tringa flavipes. The least abundant were Tryngites subruficolis, Limosa haemastica, Tringa melanoleuca and Actitis macularia. Sixteen species were migrants from the Northern Hemisphere, two were migrants from the Southern Hemisphere, and two were residents. Seven species were recorded regularly, five were recorded sporadically, and eight were recorded occasionally. Four Nearctic species were recorded in June and July most likely indicating the presence of non-breeding immature. The number of species and the number of individuals probably fluctuated due to migration or movements between neighbouring beaches. The Comprida Island beach is important migration stopover and wintering sites for many shorebirds in south São Paulo and should be a focus of conservation efforts, especially given the increasing development pressure that threatens these areas.
\end{abstract}

Keywords: monthly fluctuations, Ilha Comprida, Scolopacidae, Charadriidae.

BARBIERI, E., DELCHIARO, R.T.C. \& BRANCO, J.O. Flutuações mensais na abundância dos Charadriidae e Scolopacidae da praia da Ilha Comprida, São Paulo, Brasil. Biota Neotrop. 13(3): http://www.biotaneotropica. org.br/v13n3/pt/abstract?inventory+bn02013032013

Resumo: Foram registradas as freqüências de ocorrências e as flutuações mensais das famílias Charadriidae e Scolopacidae ao longo de um transecto de $70 \mathrm{~km}$ de praia entre o Boqueirão Sul e o Boqueirão Norte na Ilha Comprida, estado de São Paulo, durante o período de um ano (Janeiro a dezembro de 2010). Um total de 12.153 indivíduos de aves foram contados com a maior abundância ocorreu entre outubro e abril e a mais baixa entre maio a setembro. Das 20 espécies registradas as mais abundantes foram Charadrius semipalmatus, Charadrius colaris, Vanellus chilensis e Tringa flavipes. As menos abundantes foram Tryngites subruficolis, Limosa haemastica, Tringa melanoleuca e Actitis macularia. Dezesseis espécies eram migrantes do Hemisfério Norte, duas migrantes do Hemisfério Sul, e duas residentes. Sete espécies foram registradas regularmente, cinco esporadicamente e oito foram ocasionais. Quatro espécies neárticas foram registradas em Junho e julho, provavelmente indicando a presença de indivíduos imaturos não reprodutores. O número de espécies e o número de indivíduos provavelmente flutuaram devido a migração ou movimentos entre as praias vizinhas. A praia da Ilha Comprida é um importante sítio de parada durante a migração para muitas aves de praia na costa Sul do estado de São Paulo. Por esse motivo, devem ser feitos esforços de preservação, especialmente tendo em conta a crescente pressão de desenvolvimento que ameaça essa região.

Palavras-chave: Alutuação mensal, Ilha Comprida, Scolopacidae, Charadriidae. 


\section{Introdução}

Áreas costeiras são ecossistemas com elevada produtividade primária que associada à complexidade ambiental contribuem para as atividades de alimentação, descanso e nidificação das aves aquáticas (Warnock et al. 2002). A crescente ocupação humana sem planejamento adequado, associada à falta de esclarecimento, tem provocado acentuada alteração da paisagem costeira, perda de biodiversidade e degradação das estruturas biológicas das comunidades (Powell \& Powell 1986, Butler 1997, Warnock et al. 2002) Como resposta à essas modificações, as porções remanescentes das paisagens tem se tornado cada vez menores e mais isoladas, causando impacto sobre a elevada diversidade de aves marinhas costeiras, limícolas e habitantes das bordas (Sick 1997, Warnock et al. 2002).

O Brasil possui um extenso litoral com aproximadamente 8.000 $\mathrm{km}$ de costa (Ab'Saber 2001), onde as praias arenosas constituem um dos ambientes predominantes, frequentemente delimitadas na sua parte superior por um sistema de dunas frontais ou costeiras (Barbieri et al. 2003). Este ambiente constitui importantes áreas de descanso e forrageamento para aves das famílias Charadriidae e Scolopacidae. Sazonalmente o Brasil recebe grande contingente de aves migratórias vindas dos Hemisférios Norte e Sul (Morrison \& Ross 1989, Sick 1997, Alves 2007, Costa \& Sander 2008, Costa et al. 2011, Petry et al. 2012, Scherer \& Petry 2012).

Esses deslocamentos são mais evidentes com a proximidade do inverno no Hemisfério Norte, quando a redução na oferta de alimento e fatores endógenos indicam o momento da migração nas aves aquáticas (Hayman et al. 1986, Azevedo Junior et al. 2002, Costa et al. 2011, Petry et al. 2012, Scherer \& Petry 2012).

Os migrantes que abandonam a América do Norte durante o inverno utilizam várias rotas rumo às áreas de alimentação na América do Sul (Morrison 1984, Morrison \& Ross 1989, Myers et al. 1990, Sick 1997, Alves 2007, Costa \& Sander 2008, Costa et al. 2011, Petry et al. 2012, Scherer \& Petry 2012) sendo que uma das mais utilizada pelas batuíras (Charadriidae) e maçaricos (Scolopacidae) inclui a Ilha Comprida, no litoral Sul de São Paulo (Barbieri \& Paes 2008). Na Ilha Comprida, a praia com substrato arenoso é a principal área utilizada pelas aves migratórias (Barbieri \& Pinna 2005), bem como local de reprodução de Charadrius collaris e Himantopus paliatus (Barbieri \& Delchiaro 2009). Além das migrantes do Norte na Ilha Comprida também ocorrem aves que se deslocam a partir do Hemisfério Sul, as migrantes austrais como Charadrius modestus, que visitam a região entre maio a setembro (Barbieri \& Paes 2008).

Entre os Charadriidae e Scolopacidae que utilizam essa área como ponto de parada, Pluvialis squatarola, P. dominica, Charadrius semipalmatus deslocam-se do Hemisfério Norte chegando no Brasil no começo de setembro, enquanto que $C$. falklandicus, $C$. modestus, Oriophos ruficollis vem do Sul e são aves que aparecem no inverno no litoral brasileiro (Sick 1997).

Estudos de outros autores citam a ocorrência de espécies da família Charadriidae e Scolopaciidae para todo o litoral brasileiro (Vooren \& Chiaradia 1990, Sick 1997, Sanabria \& Brusco 2011), porém não quantificam precisamente o número de indivíduos e as áreas preferenciais que costumam ocorrer ao longo do ano. Trabalhos como os de Costa \& Sander (2008), Manuel et al. (2011a), Scherer \& Petry (2012) quantificam a variação temporal para o litoral gaúcho e catarinense, entretanto, ainda existem lacunas para outras regiões do Brasil, Assim, nosso conhecimento é ainda muito esparso sobre as áreas preferenciais de descanso e forrageio das aves dessa família ao longo do litoral Sudeste brasileiro.

A Ilha Comprida situa-se no Bioma da Mata Atlântica que se encontra entre os cinco "hotspots" mais ameaçados do mundo
(Meyers et al. 2000), sendo uma das regiões com maior prioridade de conservação do planeta. Apesar da abundância e diversidade de aves migratórias registradas nessa região, até o momento, existem poucas informações sobre as flutuações mensais das batuíras e dos maçaricos (Barbieri \& Pina 2005, Barbieri \& Paes 2008). Por esse motivo, o presente trabalho teve como objetivo analisar as flutuações mensais na abundância dos Charadriidae e Scolopacidae da praia da Ilha Comprida, durante o período de janeiro a dezembro de 2010.

\section{Material e Métodos}

\section{1. Área de estudo}

No extremo Sul do estado de São Paulo ocorre o recuo da escarpa da Serra do Mar, formando a bacia hidrográfica do rio Ribeira de Iguape, cuja foz marca o limite Norte do Complexo Estuarino-lagunar de Cananéia-Iguape-Paranaguá, estando a Ilha Comprida situada na região central. Esta ilha possui mais de $70 \mathrm{~km}$ de comprimento, com 3 $\mathrm{km}$ de largura em média, entrecortada por pequenos riachos, tornandose um grande atrativo para aves e outros animais (Figura 1). A praia da Ilha Comprida é constituída de extensa faixa arenosa paralela à linha da costa, com sedimentos de granulação fina, homogênea e baixa declividade, o que a caracteriza como do tipo dissipativo (Barbieri \& Cavalheiro 2000). A Ilha Comprida é uma ilha de barreira quaternária de sedimentação recente, predominantemente marinha (Suguio \& Martins 1987), formada pelo acúmulo de materiais arenosos (Tessler 1988).

As marés astronômicas têm uma altura de aproximadamente 1,50 metros, com uma marcante influência dos ventos no seu nível. A praia tem pouca declividade, resultando em uma zona de varrido com aproximadamente 20 metros de extensão havendo altas densidades de invertebrados (Tessler \& Souza 1998) que podem servir como alimento para as aves migratórias.

A vegetação é composta basicamente por restingas, mangues, brejos, dunas, praias e matas da planície atlântica, juntamente com sua fauna residente e com as aves visitantes do Hemisfério Norte e Sul, formam um complexo ecossistema, onde ainda podem ser encontradas espécies de animais ameaçadas de extinção, como o papagaio-de-cara-rocha (Amazona brasiliensis) e o macuco (Tinamus solitarius) (Barbieri \& Paes 2008) e ainda vulneráveis como o pirupiru (Haematopus palliatus) (Barbieri \& Delchiaro 2009).

A Ilha Comprida é considerada o principal ponto de parada dos Charadriidae e Scolopacidae migratórios no Sudeste brasileiro, devido a extensão da praia $(70 \mathrm{~km})$, amplitude de maré e composição do substrato (Barbieri \& Paes 2008). A parte voltada para o continente constitui-se de manguezais com planície intermareais, fazem deste um ambiente ideal para alimentação, descanso e restabelecimento dos migrantes (Barbieri \& Mendonça 2005, 2008). Além disso, a ilha integra o Complexo estuarino-lagunar de Cananéia-IguapeParanaguá, que é um dos ambientes mais produtivos do Atlântico Sul, ainda está em bom estado de preservação.

\section{Metodologia}

Os censos dos Charadriidae e Scolopacidae foram efetuados utilizando o método itinerário fixo (Bibby et al. 1992). Durante o qual a praia da Ilha Comprida foi percorrida de carro, com velocidade média de $40 \mathrm{~km} / \mathrm{h}$, seguindo uma transecção de $70 \mathrm{~km}$ por 200 metros pré-estabelecidos seguindo metodologia proposta por Vooren \& Chiaradia 1990, Bibby et al. 1992, Barbieri \& Mendonça 2005. O trajeto percorrido foi sempre iniciado na parte Sul da ilha (Boqueirão Sul) em direção ao Norte (Canal de Icapara). As aves avistadas foram identificadas com o auxilio de binóculos 7X50 e 20X60, contadas, registradas e fotografadas. As saídas foram realizadas semanalmente, 


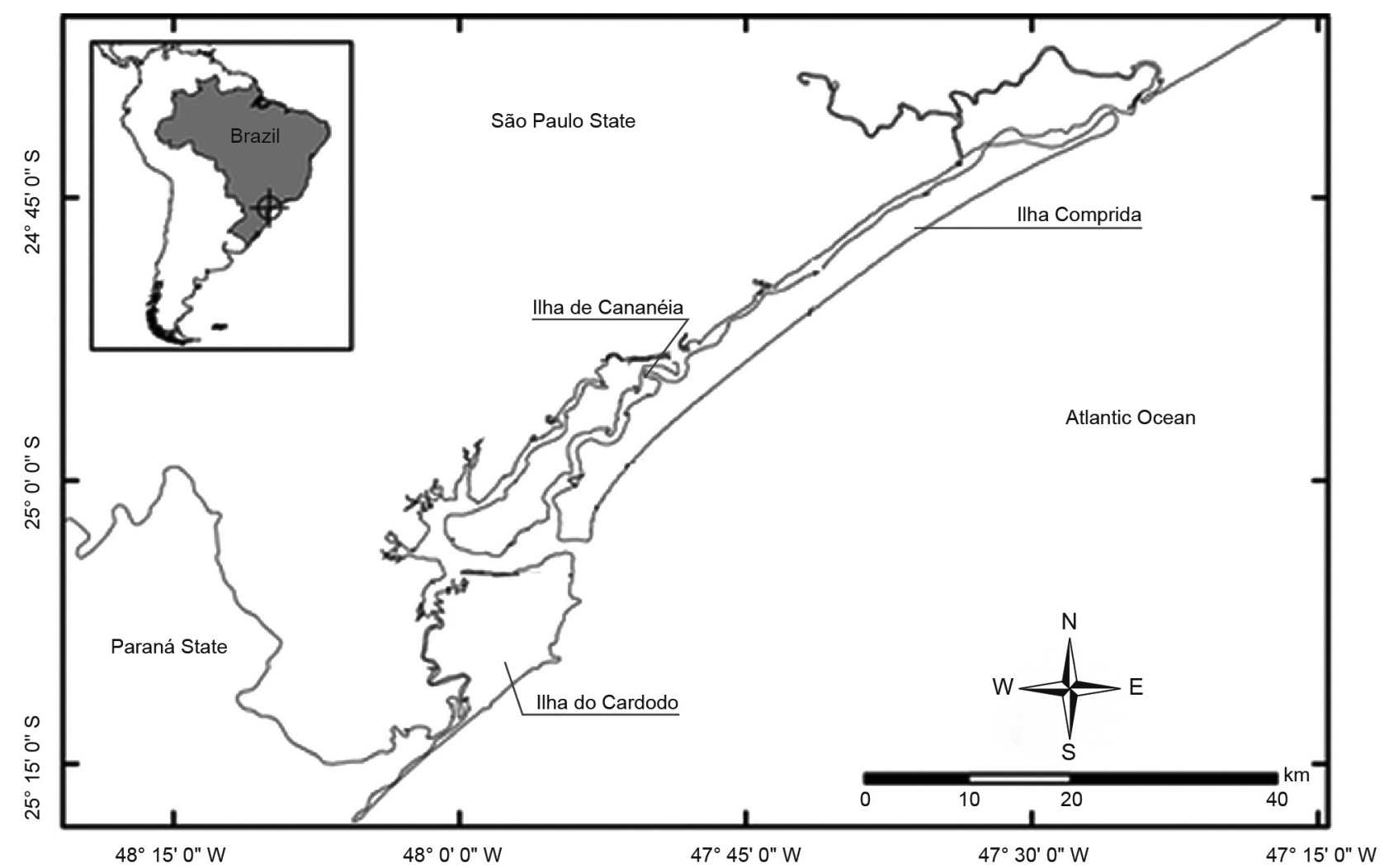

Figura 1. Localização da Ilha Comprida no Complexo Estuarino-Lagunar de Cananéia-Iguape. Fonte: Santos \& Rosso (2008).

Figure 1. Localization of Ilha Comprida at Cananéia-Iguape estuary. Source: Santos \& Rosso (2008).

alternando manhã e tarde com duração de duas horas de observação. Os 43 censos realizados totalizaram 86 horas (2 horas/visita) de observação e ocorreram, entre janeiro e dezembro de 2010. O período matutino iniciou as 8:30 h finalizando-se as 10:30 h, já o período vespertino iniciou as 14:00 h e finalizando-se as 16:00 $\mathrm{h}$.

Foi calculada a Frequência de Ocorrência (FO) das espécies registradas por mês. A FO foi definida como a percentagem do número de indivíduos de uma espécie em relação ao total dos indivíduos contados. A frequência foi calculada com o número de visitas em que a espécie foi encontrada sobre o número de visitas efetuadas, multiplicadas por 100. As espécies foram categorizadas de acordo com a Tabela 1 (Dajoz 1978), em regular: presentes em mais de 50\% das visitas, esporádica: entre 25 a $50 \%$ e ocasionais: em menos de $25 \%$ das espécies nas visitas.

A comparação das flutuações populacionais ao longo do período foram testadas quanto a normalidade pelo teste estatístico ShapiroWilk, quando a distribuição mostrou-se normal utilizou-se ANOVA $(p<0,05)$ (ZAR 1999). Entretanto, quando a distribuição não foi normal utilizou-se o teste não paramétrico Kruskal Wallis.

\section{Resultados}

Durante o período estudado foram registrados 12.153 indivíduos, sendo sete espécies de Charadriidae (84,0\% das aves) e 13 espécies de Scolopacidae (16,0\%) (Tabela 1). Não houve diferença significativa entre a média de indivíduos e os períodos da manhã e tarde (ANOVA) (Figura 2).

Das 20 espécies registradas, duas são consideradas pelo CRBO (Comitê... 2011) aves residentes na Ilha Comprida, 16 migrantes do Hemisfério Norte e duas do Hemisfério Sul (Tabela 2). Em geral, as amostragens foram dominadas por poucas espécies, dentre elas destacam-se Charadrius semipalmatus, presente em 54,36\% das amostragens e as duas espécies residentes (V. chilensis e C. collaris), ambas Charadriidae que contribuíram com $17,02 \%$ e $10,26 \%$ respectivamente das aves contadas (Tabela 1). Entre os Scolopacidae mais abundantes, Calidris alba e C. fuscicolis representaram entre 5,66 e 5,33\%, respectivamente do total indivíduos (Tabela 1).

As batuíras e maçaricos amostrados apresentaram amplas flutuações e a categorização das espécies está apresentada na Tabela 2. Entre as sete espécies de Charadriidae registrados quatro foram categorizados como regulares nas amostragens, duas ocasionais, e uma esporádica. Das 13 espécies de Scolopacidae, três foram regulares, quatro esporádicas e seis ocasionais (Tabela 2).

Durante o período de amostragens ocorreram flutuações mensais acentuadas na população de $C$. semipalmatus da Ilha Comprida com incremento moderado a partir de janeiro até alcançar as maiores abundâncias médias em abril $(237,2 \pm 374,5)$, seguidas pela redução no número de registros e com acentuada queda em agosto $(22,4 \pm 17,6)$, com oscilações até dezembro $(123,3 \pm 58,0)$ (Figura 3). Através do teste estatístico ANOVA pode-se constatar que os números de indivíduos nos meses de maio, junho, julho e agostos foram significativamente diferentes dos outros meses.

A maior média mensal para $C$. collaris ocorreu em junho $(43,5 \pm 6,1)$ e a menor em dezembro $(2,0)$ (Figura 4). Comparandose os meses de janeiro, novembro e dezembro, observou-se que o número de indivíduos dessa espécie foi estatisticamente diferente (ANOVA) dos outros meses estudados.

A população de $V$. chilensis apresentou uma tendência moderada de incremento de janeiro a março, seguido de oscilações até alcançarem as maiores abundâncias em julho $(62,1 \pm 55,6)$ e 
Tabela 1. Número total de espécies mais abundantes contadas durante o período estudado. ST - status (MN - Migrante do Norte, MS - Migrante do Sul, RE - Residente). N - Número total de indivíduos, M - Média da abundância, SD - Desvio padrão da abundância, FO - Freqüência de Ocorrência).

Table 1. Total number of the species more abundant counted in all the study. CE - ecological category (MN - North migration, MS - South migration, RE - Resident). N - total number of individuals, M - Abundance average, SD - Standard deviation of abundance, FO - Occurrence frequency).

\begin{tabular}{|c|c|c|c|c|c|c|}
\hline Família / Espécie & ST & Frequência & $\mathbf{N}$ & M & SD & FO \\
\hline \multicolumn{7}{|l|}{ Charadriidae } \\
\hline Vanellus chilenses & RE & Regular & 2069 & 30,42 & 31,96 & 17,02 \\
\hline Pluvialis dominica & $\mathrm{MN}$ & Regular & 229 & 9,16 & 10,66 & 1,88 \\
\hline Pluvialis squatarola & $\mathrm{MN}$ & Esporádica & 53 & 3,53 & 2,64 & 0,44 \\
\hline Charadrius semipalmatus & $\mathrm{MN}$ & Regular & 6606 & 106,54 & 150,33 & 54,36 \\
\hline Charadrius collaris & $\mathrm{RE}$ & Regular & 1247 & 21,5 & 18,23 & 10,26 \\
\hline Charadrius falklandicus & MS & Ocasional & 2 & 1 & 0 & 0,02 \\
\hline Charadrius modestus & MS & Ocasional & 2 & 1 & 0 & 0,02 \\
\hline \multicolumn{7}{|l|}{ Scolopacidae } \\
\hline Limosa haemastica & $\mathrm{MN}$ & Esporádica & 3 & 3 & 0 & 0,02 \\
\hline Numenius phaeopus & $\mathrm{MN}$ & Esporádica & 9 & 2,25 & 1,89 & 0,07 \\
\hline Actitis macularius & MN & Ocasional & 2 & 1 & 0 & 0,02 \\
\hline Tringa melanolenca & $\mathrm{MN}$ & Ocasional & 2 & 1 & 0 & 0,02 \\
\hline Tringa flavipes & $\mathrm{MN}$ & Regular & 145 & 4,26 & 4,78 & 1,19 \\
\hline Arenaria interpres & $\mathrm{MN}$ & Esporádica & 30 & 5 & 4,19 & 0,25 \\
\hline Calidris canutus & $\mathrm{MN}$ & Esporádica & 218 & 16,76 & 14,07 & 1,79 \\
\hline Calidris alba & $\mathrm{MN}$ & Regular & 687 & 17,17 & 16,57 & 5,66 \\
\hline Calidris pusilla & $\mathrm{MN}$ & Ocasional & 190 & 31,66 & 42,87 & 1,56 \\
\hline Calidris fuscicolis & $\mathrm{MN}$ & Regular & 647 & 24,88 & 40,34 & 5,33 \\
\hline Calidris melanotus & $\mathrm{MN}$ & Ocasional & 4 & 1 & 0 & 0,03 \\
\hline Tryngites subruficollis & $\mathrm{MN}$ & Ocasional & 4 & 1 & 0 & 0,03 \\
\hline Phalaropus tricolor & MN & Ocasional & 4 & 1 & 0 & 0,03 \\
\hline
\end{tabular}

Tabela 2. Frequência de ocorrência mensal das aves registradas na praia da Ilha Comprida de janeiro a dezembro de 2010 .

Table 2. Monthly occurrence frequency of birds recorded at Ilha Comprida beach between January to December 2010 .

\begin{tabular}{|c|c|c|c|c|c|c|c|c|c|c|c|c|}
\hline Família / Espécie & Jan & Fev & Mar & Abr & Mai & Jun & Jul & Ago & Set & Out & Nov & Dez \\
\hline \multicolumn{13}{|l|}{ Charadriidae } \\
\hline Vanellus chilenses & 4,8 & 5,5 & 20,5 & 9,0 & 38,7 & 21,8 & 46,8 & 45,0 & 11,9 & 11,9 & 11,7 & 6,5 \\
\hline Pluvialis dominica & 0,2 & - & 0,1 & 0,2 & 0,6 & - & - & - & 3,0 & 3,0 & 7,3 & 10,1 \\
\hline Pluvialis squatarola & 0,2 & 0,2 & 0,2 & - & - & 0,2 & - & - & 0,6 & 0,6 & 1,0 & 3,1 \\
\hline Charadrius semipalmatus & 81,2 & 85,6 & 73,4 & 71,8 & 21,2 & 29,6 & 21,7 & 20,2 & 35,7 & 35,7 & 53,0 & 35,1 \\
\hline Charadrius collaris & 1,8 & 3,4 & 3,0 & 4,7 & 34,3 & 45,9 & 30,8 & 33,5 & 9,5 & 9,5 & 1,1 & 1,5 \\
\hline Charadrius falklandicus & - & - & - & - & - & - & 0,1 & 0,1 & - & - & - & - \\
\hline Charadrius modestus & - & - & - & - & - & - & 0,1 & 0,2 & & - & - & - \\
\hline Scolopacidae & - & - & - & - & - & - & - & - & - & - & - & - \\
\hline Limosa haemastica & - & - & - & - & - & - & - & - & - & - & - & 0,4 \\
\hline Numenius phaeopus & - & - & - & - & 0,2 & - & - & - & - & - & 0,7 & - \\
\hline Actitis macularius & - & 0,1 & - & - & - & & - & - & - & - & 0,1 & - \\
\hline Tringa flavipes & 0,1 & 0,1 & 1,3 & 1,5 & 2,9 & 1,0 & 0,4 & 0,5 & 1,9 & 1,9 & 2,7 & 0,1 \\
\hline Tringa melanolenca & - & -- & - & - & 0,2 & - & - & - & - & - & - & - \\
\hline Arenaria interpres & - & - & 0,1 & - & - & - & - & - & - & - & 1,2 & 2,1 \\
\hline Calidris canutus & - & - & - & 0,7 & - & - & - & - & 7,3 & 7,3 & 2,3 & 4,5 \\
\hline Calidris alba & 11,1 & 3,1 & 1,1 & 1,6 & 1,5 & 1,5 & - & 0,4 & 12,2 & 12,2 & 10,1 & 12,3 \\
\hline Calidris pusilla & - & 0,4 & - & & 0,4 & - & - & - & 9,0 & 9,0 & - & - \\
\hline Calidris fuscicolis & 0,7 & 1,8 & 0,4 & 10,7 & - & - & - & - & 8,2 & 8,2 & 9,0 & 24,4 \\
\hline Calidris melanotus & - & - & - & - & - & - & - & - & 0,2 & 0,2 & - & - \\
\hline Tryngites subruficollis & - & - & - & - & - & - & - & - & 0,2 & 0,2 & - & - \\
\hline Phalaropus tricolor & 0,1 & - & - & - & - & & & & 0,1 & & 0,1 & 0,1 \\
\hline
\end{tabular}




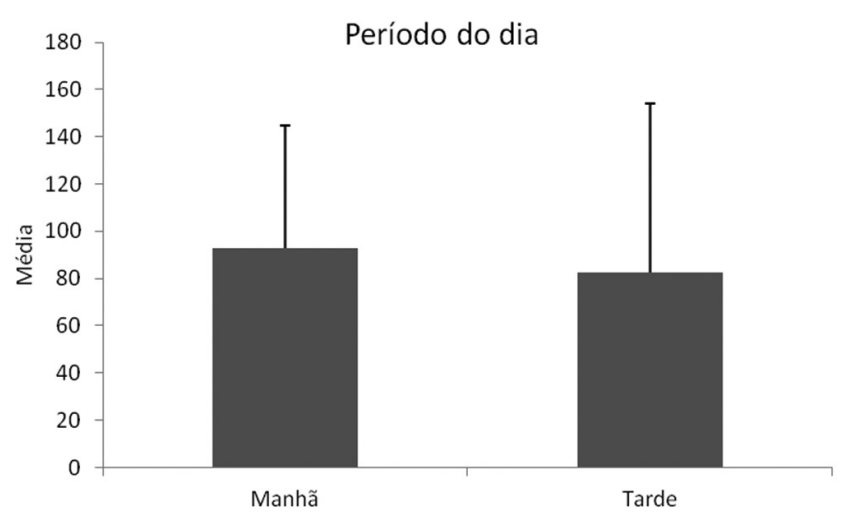

Figura 2. Médias do número de indivíduos nos diferentes períodos do dia (manhã e tarde) observados na praia da Ilha Comprida. As barras representam os respectivos desvios padrões de cada média.

Figure 2. Individual averages of birds in different periods of the day (morning and afternoon) observed at Ilha Comprida beach. The bars represent the respective standard deviations.

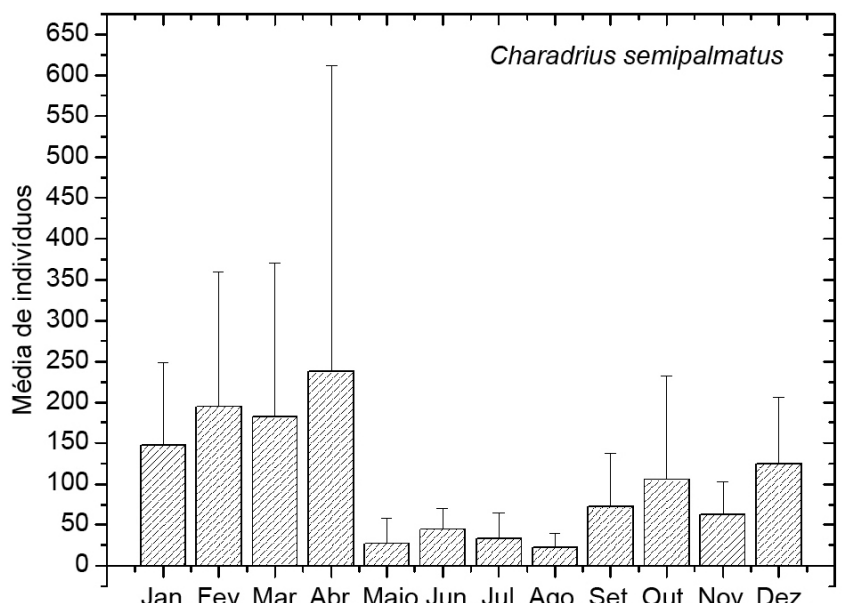

Figura 3. Médias mensais (barras representa desvio padrão) de Charadrius semipalmatus na Ilha Comprida (SP), Brasil, durante o ano de 2010.

Figure 3. Monthly average count $( \pm \mathrm{SD})$ of Charadrius semipalmatus during the 2010 study at Ilha Comprida Beach on the coast of São Paulo State, Brazil.

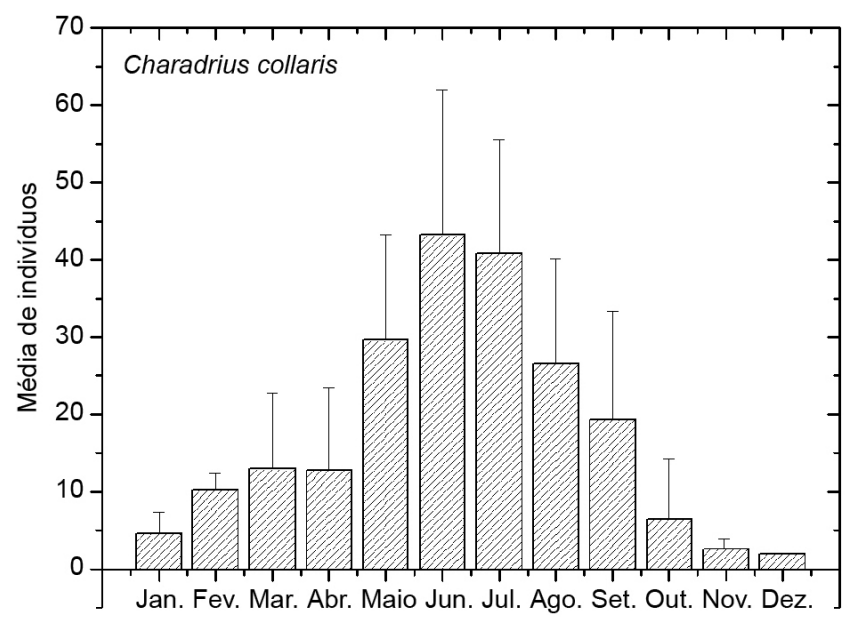

Figura 4. Médias mensais (barras representa desvio padrão) de Charadrius collaris na Ilha Comprida (SP), Brasil, durante o ano de 2010.

Figure 4. Monthly average count $( \pm \mathrm{SD})$ of Charadrius collaris during the 2010 study at Ilha Comprida Beach on the coast of São Paulo State, Brazil. queda gradual até novembro $(8,8 \pm 9,7)$ (Figura 5). A população de V. chilensis foi significativamente (ANOVA) diferente em janeiro, fevereiro e novembro ao serem comparadas com outros meses estudados.

Flutuações mensais também foram evidentes nos Scolopacidae, com os primeiros indivíduos de Calidris alba chegando na Ilha Comprida em agosto, seguido do ingresso de novos migrantes até dezembro e do abandono gradativo até junho (Figura 6). Padrão semelhante de ocorrência foi observado na população de C. fuscicolis que iniciou a ocupação do sítio a partir de setembro e deixaram à ilha em meados de abril (Figura 7), o teste Kruskal Wallis demonstrou que para as duas espécies os meses de maio, junho, julho e agosto, foram estatisticamente diferentes dos outros meses estudados. Já a população de C. canutus esteve presente de setembro a dezembro, regressando novamente em abril (Figura 8).

As espécies Calidris melanotus, Tryngites subruficollis, Charadrius falklandicus e Charadrius modestus foram raras na praia da Ilha sendo registradas apenas em duas ocasiões (Tabela 1).

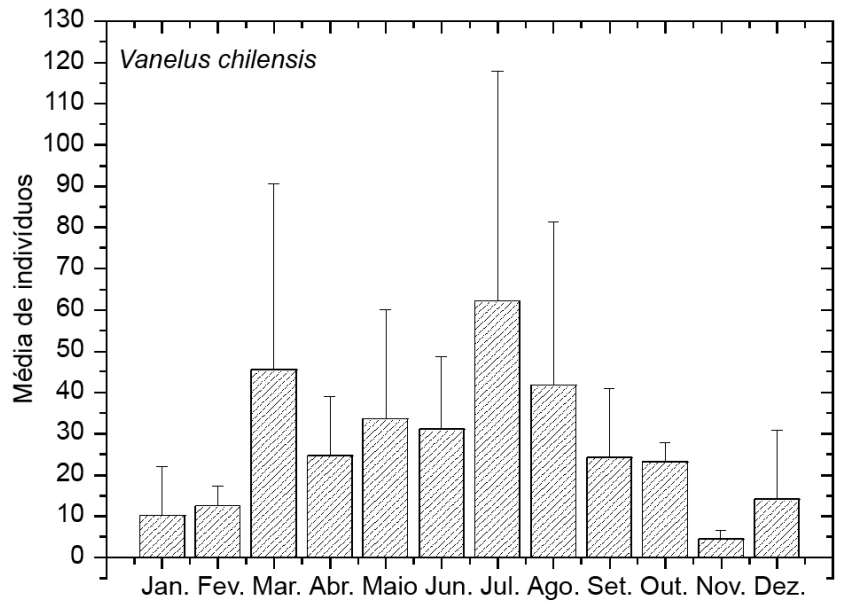

Figura 5. Médias mensais (barras representa desvio padrão) de Vanelus chilensis na Ilha Comprida (SP), Brasil, durante o ano de 2010.

Figure 5. Monthly average count $( \pm \mathrm{SD})$ of Vanelus chilensis during the 2010 study at Ilha Comprida Beach on the coast of São Paulo State, Brazil.

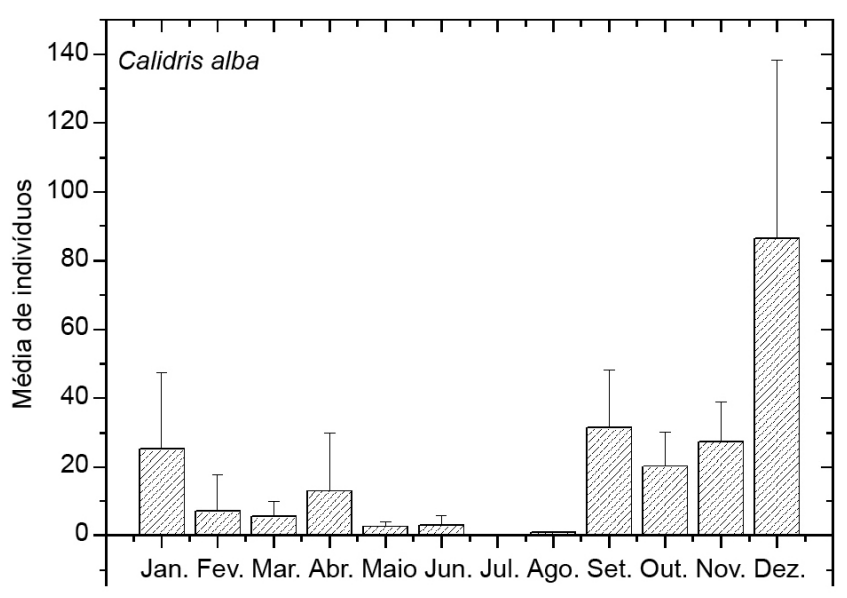

Figura 6. Médias mensais (barras representa desvio padrão) de Calidris alba na Ilha Comprida (SP), Brasil, durante o ano de 2010.

Figure 6. Monthly average count $( \pm \mathrm{SD})$ of Calidris alba during the 2010 study at Ilha Comprida Beach on the coast of São Paulo State, Brazil. 


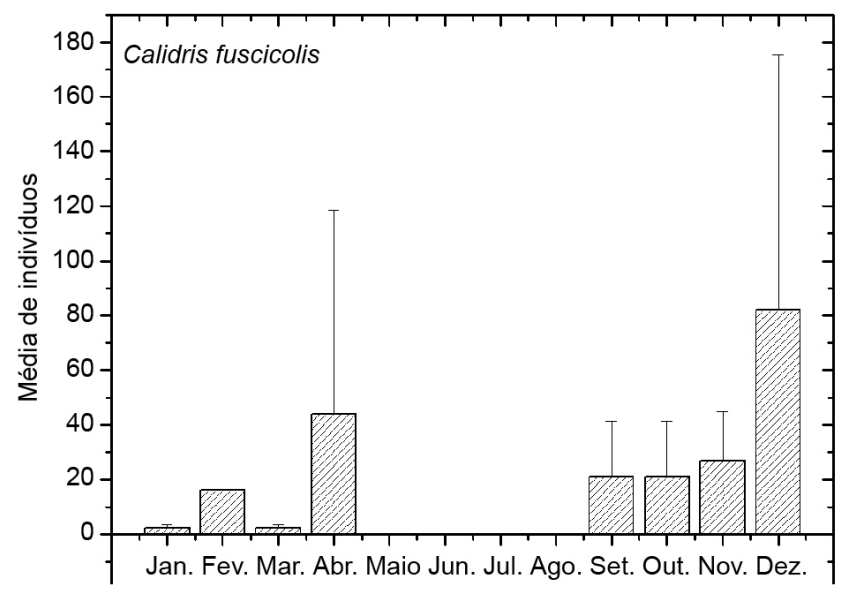

Figura 7. Médias mensais (barras representa desvio padrão) de Calidris fuscicolis na Ilha Comprida (SP), Brasil, durante o ano de 2010.

Figure 7. Monthly average count $( \pm \mathrm{SD})$ of Calidris fuscicolis during the 2010 study at Ilha Comprida Beach on the coast of São Paulo State, Brazil.

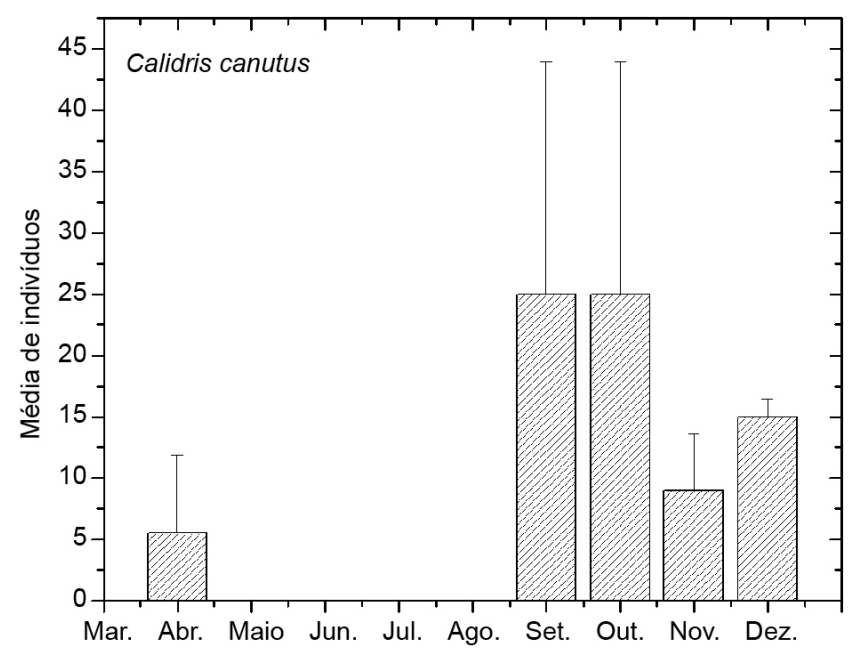

Figura 8. Médias mensais (barras representa desvio padrão) de Calidris canutus na Ilha Comprida (SP), Brasil, durante o ano de 2010.

Figure 8. Monthly average count $( \pm \mathrm{SD})$ of Calidris canutus during the 2010 study at Ilha Comprida Beach on the coast of São Paulo State, Brazil.

\section{Discussão}

Durante o período deste estudo foram observados 12.153 indivíduos das famílias Charadriidae e Scolopacidae, sendo que das 20 espécies registradas 18 eram migrantes, o que demonstra que a região é um importante ponto de parada e invernada para essas aves. A presença dessas espécies confirma a importância da praia da Ilha Comprida na costa Sul do estado de São Paulo como relevante ponto de parada para aves migratórias principalmente as do Hemisfério Norte.

A presença de aves em uma determinada região depende de fatores como ambiente e época do ano (McWhinter \& Beaver 1977). Assim, a soma dos deslocamentos sazonais, juntamente com as espécies residentes compõe a avifauna de um território. A qual na Ilha Comprida é composta por diversas aves migratórias. Entretanto, a ocupação desordenada das áreas costeiras vem forçando o deslocamento dos sítios de forrageio e nidificação, acarretando na exclusão de espécies de algumas regiões litorâneas (Hvenegaard \&
Barbieri 2010). Assim sendo, torna-se imperativo para a preservação das aves de praia a preservação também, de suas áreas de parada e invernada.

Nesse cenário, a praia de Ilha Comprida vem sendo ocupada desordenadamente pela especulação imobiliária, além de ser utilizada por turistas, como via de acesso, com trânsito livre de veículos. Essa presença humana gera distúrbios para as algumas espécies de aves que descansam durante a maré alta (Hvenegaard \& Barbieri 2010), obrigando-as a voarem de um lado a outro, acarretando em perda desnecessária de energia (Barbieri 2007), que poderá comprometer o processo migratório dos indivíduos afetados e a composição das aves deste ambiente.

Charadrius collaris habita praias abertas, arroios, locais com areia ou lama e zonas de vegetação pioneira, forrageia durante o verão sobre bancos de pequenos crustáceos e vermes marinhos, no inverno ocupa regiões mais distantes d'água como as dunas, utilizando também o local para reprodução durante a primavera (Sick 1997). Essa espécie foi regular na Ilha Comprida, ocupando a região de praia arenosa com grande biomassa de invertebrados, que serve de alimento para as aves de praia (Barbieri \& Hvenegaard 2008). A abundância média mensal de $C$. collaris sugere flutuações com um padrão definido de ocupação da ilha, iniciando em janeiro até pequena pausa entre março-abril, seguido incremento até alcançar as maiores abundâncias médias em junho e deslocamento gradativo da praia amostrada até atingir a menor abundância em dezembro. Lara-Resende \& Leeuwenberg (1987) relatam que encontraram na Lagoa do Peixe (RS) C. collaris reproduzindo de novembro a janeiro, também observaram forrageando nas proximidades dos ninhos, e na praia quando chegava o inverno. Da mesma maneira Belton(1984), Costa \& Sander (2008) e Scherer. \& Petry (2012) observaram um maior número da espécie na praia durante os meses de junho, julho e agosto no Rio Grande do Sul. O aumento do número de indivíduos na Ilha Comprida no período de maio a setembro pode ser explicado, por essa espécie não estar em época reprodutiva. Durante a reprodução (outubro a março) essa espécie está forrageando próximo a seu ninho, que são construídos nas dunas e bernas.

O quero-quero (Vanellus chilensis) é uma espécie residente no país, geralmente costuma alimentar-se de invertebrados, larvas de insetos e peixes (Sick 1997), podendo utilizar ambientes modificados pelo homem (salinas e viveiros de cultivo) como suporte alimentar (Nascimento \& Lazarrábal 2000). Essa espécie esteve presente durante todas as estações do ano na Ilha Comprida, apresentando maiores densidades durante a primavera. Também foi encontrada ao longo do ano em praias de Santa Catarina (Navegantes e Laguna) (Schiefler \& Soares 1994), no estuário do Saco da Fazenda (SC) (Manuel et al. 2011a, b), Barra de Cunhaú (RN), onde apresentou as maiores densidades entre outubro e novembro (Nascimento \& Lazarrábal 2000). No rio Grande do Sul as maiores densidades forma em abril, maio e junho (Scherer \& Petry 2012).

As espécies Vanellus chilenses, Charadrius semipalmatus, C. collaris, Tringa flavipes foram registrados em todos os meses de amostragens, ao contrário de Limosa haemastica e Tringa melanolenca que ocorreram em apenas um mês e outras setes em duas amostragens (Tabela 1). De acordo com a mesma tabela durante os meses de junho, julho e agosto foram registradas as menores ocorrências de espécies e indivíduos e entre setembro e outubro as maiores. Os mesmos resultados foram encontrados por Scherer \& Petry (2012) para as espécies Vanellus chilenses, Charadrius semipalmatus, C. collaris e Tringa flavipes que foram observados ao longo de todo ano no Rio Grande do Sul.

De acordo com nossos resultados, Pluvialis squatarola e $P$. dominica são espécies frequentes durante os meses de setembro a dezembro (Tabela 1), e apresentam baixa densidade de janeiro a 
março, sendo ausentes nos meses de julho e agosto. A ausência nesses meses pode ser explicada pelo deslocamento para o Hemisfério Norte, pois é nessa época do ano que estão em período de reprodução (Sick 1997, Alves 2007). Comportamento semelhante foi registrado para P. dominica nas praias de Navegantes e Laguna (Schiefler \& Soares 1994), por Vooren \& Chiaradia (1990), Costa \& Sander (2008), Sanabria \& Brusco (2011), Scherer \& Petry (2012) no Rio Grande do Sul (Praia do Cassino, Lagoa do Peixe, litoral Norte do Rio Grande do Sul), e para a Argentina na Patagônia (Belton, 1984).

Constatou-se que poucos indivíduos de Charadrius semipalmatus e alguns raros de Calidris alba e Tringa flavipes invernaram na praia da Ilha Comprida. Provavelmente a maioria da população migra para as áreas reprodutivas no Hemisfério Norte. De acordo com Sick (1997) estas espécies retornam ao Hemisfério Norte para reprodução durante o nosso inverno, assim os bandos observados nos meses de junho, julho e agosto, provavelmente são formados por aves imaturas que não acompanham a sua rota migratória (Vooren \& Chiaradia 1990, Costa \& Sander 2008, Scherer \& Petry 2012). Belton (1984) relata um fenômeno similar no Sul do Brasil, onde um grupo de Calidris canutus permaneceu na região do Rio Grande do Sul durante o verão boreal (julho). Costa \& Sander (2008) registra a permanência das espécies Arenaria interpres Tringa solitária, Sterna hirundo, Tringa melanoleuca, Charadrius semipalmatus, Calidris fuscicolis e Calidris Alba para o litoral Norte do rio Grande do Sul durante o inverno austral

Calidris canutus ocorreu em baixa abundância (Tabela 1) na Ilha Comprida, sendo mais comuns em abril e de setembro a dezembro, resultados similares aos de, Belton (1984), Telino-Júnior et al. (2003) e Scherer \& Petry (2012) para outras regiões do país. Entretanto, Vooren e Chiaradia (1990) estudando aves costeiras em Rio Grande (RS), e Rodrigues (2000) no golfo de Maranhão registraram um pico de março a maio. Essas informações e nossos resultados reforçam a hipótese da Ilha Comprida ser utilizada como ponto de parada para locais de invernada mais ao Sul do país (Lagoa do Peixe) e Argentina (Morrison 1984, Vooren \& Chiaradia 1990, Telino-Júnior et al. 2003, Costa \& Sander 2008, Scherer \& Petry 2012). Bem como, para Charadrius semipalmatus, Pluvialis dominica, P. squatarola, C. alba, C. canutus e C. fuscicolis durante a migração de retorno para o Hemisfério Norte (abril) e para as áreas de forrageio do Hemisfério Sul (setembro). Também pode ser considerado um sítio de invernada para C. semipalmatus, pois além da elevada abundância nos meses de primavera e verão, ocorreu em todos os meses estudados na ilha.

As menores ocorrências das espécies e dos indivíduos ocorreram no período de junho a agosto e as maiores em setembro e outubro, sugerindo que muitas aves abandonam a Ilha Comprida no final de maio seguindo sua rota migratória para reprodução, retornando em setembro (Tabela 1). Esse registro coincide com os dados obtidos por Vooren e Chiaradia (1990) para a Praia do Cassino (RS), por Costa \& Sander (2008) e Scherer \& Petry (2012) para o litoral Norte do Rio Grande do Sul e por Manuel et al. (2011a, b) para o Saco da Fazenda(SC).

A proteção das aves migratórias das famílias Charadriidae e Scolopacidae está diretamente ligada à preservação dos seus sítios de reprodução, alimentação e repouso (Alves 2007, Manuel et al. 2011b, Barbieri \& Bete 2013). A perda ou alteração dos sítios de invernada e de repouso dessas aves pode resultar na redução e até mesmo a extinção local de algumas espécies ou a diminuição da população (Cordeiro et al. 1996, Barbieri 2007, Alves 2007, Barbieri \& Hvenegaard 2008, Hvenegaard \& Barbieri 2010, Scherer \& Petry 2012). Muitas espécies de aves interrompem seus deslocamentos migratórios para descanso e restabelecimento para continuarem viajem. Durante o deslocamento as aves migrantes requerem alta demanda energética e para isso, selecionam suas áreas de "paradas" ou pontos de "descanso", de acordo com a qualidade, produtividade e risco de predação do local (Alerstan et al. 2003, Fedrizzi et al. 2004). Moore \& Simons (1992) relatam a importância da qualidade dos habitats utilizados como ponto de descanso e alimentação para aves migratórias, especialmente aquelas que atravessam grandes barreiras geográficas durante seus deslocamentos. Assim, a energia acumulada nesses sítios é fundamental para retornarem ao Hemisfério Norte em meados de abril e para as migrantes austral em meados de outubro (Sick 1997). Nesse cenário, a Ilha Comprida atua como ponto de parada (alimentação e repouso) (Barbieri \& Paes 2008), onde o alimento obtido nas áreas de descanso fornece energia para continuar migração (Davison \& Evens 1988), incrementando as reservas essenciais ao sucesso reprodutivo nas áreas de procriação (Hvenegaard \& Barbieri 2010). Nesta dimensão, a proteção das áreas de invernada e dos pontos de parada na Ilha Comprida, como praias, lagoa, planícies intermareais (baixios) e campos de inundação, tornam-se relevante para a preservação das várias espécies de aves que transitam pela região, quer sejam residentes, migrantes setentrionais, meridionais, ou regionais.

\section{Agradecimentos}

Ao Instituto de Pesca da Secretaria da Agricultura do Estado de São Paulo que possibilitou essa pesquisa, ao CNPq (processo: 308700/2010-4) e pelas bolsas de produtividade em pesquisa dos autores.

\section{Referências Bibliográficas}

AB'SABER, A.N. 2001. Litoral do Brasil. Metalivros, São Paulo, p.287.

ALERSTAN, T., HEDENSTRÖM, A.E. \& ÄKESSON, S. 2003. Long-distance migration: evolution and determinants. Oikos 103:247-260.

ALVES, M.A S. 2007. Sistemas de migrações de aves em ambientes terrestres no Brasil: exemplos, lacunas e propostas para o avanço do conhecimento. 2007. Rev. Bras. Ornitol. 15: 243-250.

AZEVEDO JUNIOR, S.M., DIAS, M.M. \& LARRAZÁBAL, M.E. 2002. Plumagens e mudas de Charadriiformes (Aves) no litoral de Pernambuco, Brasil. Rev. Bras. Zool. 18(3):657-672.

BARBIERI, E., MENDONÇA, J.T. \& XAVIER, S.C. 2003. Importance of Ilha Comprida (São Paulo State, Brazil) for the sanderlings (Calidris alba) migration. J. Coast. Res. (35 special issue):121-130.

BARBIERI, E. \& CAVALHEIRO, F. 2000. Diagnóstico do impacto ambiental na parte Sul da Ilha Comprida (litoral Sul do Estado de São Paulo). In Simpósio de Ecossistemas Brasileiros. Vitória, v.1. p.338-348.

BARBIERI, E. \& PINNA, F.V. 2005. Distribuição da batuírade-coleira (Charadrius collaris) durante o período de 1999 a 2001 na praia da Ilha Comprida. Rev. Bras. Ornitol. 13(2):25-31.

BARBIERI, E. \& MENDONÇA, J.T. 2005. Distribution and abundance of Charadriidae at Ilha Comprida, São Paulo State, Brazil. J. Coastal Res. 21(2): e1-e10.

BARBIERI, E. 2007. Seasonal abundance of shorebirds at Aracaju, Sergipe, Brazil. Wader Stud. Group Bull. 113:40-46.

BARBIERI, E. \& MENDOÇA, J.T. 2008. Seasonal abundance and distribution of larids at Ilha Comprida (São Paulo State, Brazil). J. Coastal Res. 24(1A):70-78.

BARBIERI, E. \& PAES, E.T. 2008. The birds at Ilha Comprida beach (São Paulo State, Brazil): a multivariate approach. Biota Neotrop. 8(3): http:// www.biotaneotropica.org.br/v8n3/en/abstract?article+bn00408032008 (último acesso em 19/04/2011).

BARBIERI, E. \& HVENEGAARD, G.T. 2008. Seasonal Occurrence and Abundance of Shorebirds at Atalaia Nova Beach in Sergipe State, Brazil. Waterbirds 31(4):636-644. 
BARBIERI, E. \& DELCHIARO, R.T.C. 2009. Nesting of the American Oystercatcher Haematopus palliatus Temminck 1820, Haematopodidae in the southern coast of São Paulo State, Brazil. Biota Neotrop. 9(4): http://www.biotaneotropica.org.br/v9n4/en/abstract? shortcommunication+bn02609042009 (último acesso em 02/05/2013)

BARBIERI, E. \& BETE, D. 2013. Occurrence of Stercorarius pomarinus (Temminck, 1815, Charadriiformes: Stercorariidae) in Cananéia estuary, Southern Coast of São Paulo State, Brazil. Biota Neotrop. 13(1): http:// www.biotaneotropica.org.br/v13n1/en/abstract?article+bn00613012013 (último acesso em 02/05/2013).

BELTON, W. 1984. Birds of Rio Grande do Sul, Brasil. Part I. Rheidae through Furmariidae. Bull. Amer. Mus. Nat. Hist. 178:389-636.

BIBBY, J.C., BURGUES, N.D. \& HILL, D.A. 1992. Bird Census Techniques. Academic Press, London, 127p.

BUTLER 1997. The Great Blue Heron. University of British Columbia Press, Vancouver.

CORDEIRO, P.H.C., FLORES, J.M. \& NASCIMENTO, J.L.X. 1996 Análise das recuperações de Sterna hirundo no Brasil entre 1980 e 1994. Ararajuba 4:3-7.

COSTA, E.S. \& SANDER, M. 2008. Variação sazonal de aves costeiras (Charadriiformes e Ciconiiformes) no litoral Norte do Rio Grande do Sul, Brasil. Biodiver. Pampeana (Online), 6: 3-8.

COSTA, E.S., AYALA L., SUL, J.A.I., CORIA, N.R., SÁNCHEZSCAGLIONI, R.E., ALVES, M.A.S., PETRY, M.V. \& PIEDRAHITA, P. 2011. Antarctic and Sub-Antarctic seabirds in South America: A Review. Oecol. Baust. 15:59-68.

COMITÊ BRASILEIRO DE REGISTROS ORNITOLÓGICOS - CRBO 2011. http://www.cbro.org.br/CBRO/index.htm (último acesso em 22/07/2012)

DAJOZ, R. 1978. Ecologia Geral. 3. ed. Vozes, Petrópolis.

DAVISON, N. \& EVENS, P. 1988. Prebreeding acumulation of fat and muscle protein by Artic nesting shorebirds. Proc. Int. Ornithol. Congr. 19:342-352.

FEDRIZZI, C.E., AZEVEDO JUNIOR, S.M. \& LARAZZÁBAL, M.E.L. 2004. Body mass and acquisition of breeding plumage of wintering Calidris pusilla (Linnaeus) (Aves, Scolopacidae) in the coast of Pernambuco, north-eastern Brazil. Rev. Bras. Zool. 21(2):249-256.

HVENEGAARD, G.T. \& BARBIERI, E. 2010. Shorebirds in the State of Sergipe, northeast Brazil: potential tourism impacts. Rev. Bras. Ornitol. 18(3):169-175.

HAYMAN, P., MARCHANT, J. \& PRATER, T. 1986. Shorebirds. An identification guide to the waders of the world. Christopher Helm, London, 412p.

LARA-RESENDE, S.L. \& LEEUWENBERG, D.L. 1987. Ecological studies of Lagoa do Peixe. International Report 4. World Wildlife FoundationWWF/US, District of Columbia, Washington.

MANUEL, F.C., BRANCO, J.O. \& BARBIERI, E. 2011a. Composição da avifauna aquática do Saco da Fazenda, Itajaí-SC. Mundo Saúde. 35(1):31-41.

MANUEL, F.C., BRANCO, J.O. \& BARBIERI, E. 2011b. Flutuações sazonal e diária das aves aquáticas no Saco da Fazenda, Itajaí-SC. Mundo Saúde. $35(1): 47-54$.

McWHINTER, D.W. \& BEAVER, D.L. 1977. Birds of the capital count area of Michigan, whith seassonal and historical analyses. Publ. Museum Mich. State Urriv., Biol. Ser. 5:353-442.
MEYERS, N.R.A., MITTERMEIER, C.G., MITTERMEIER, G.A., FONSECA, B. \& KENT, J. 2000. Biodiversity hotspots for conservation priority. Nature 403:853-858.

MOORE, F.R. \& SIMONS, T.R. 1992. Habitat suitability and stopover ecology of Neotropical landbird migrants. In Ecology and conservation of neotropical migrant landbirds (J. M. Hagam III \& D. W. Johnston, eds.) Smithsonian Instituition Press, Washington, p.345-355.

MYERS, J.P., SALLABERRY, M.A., ORTIZ, E., CASTRO, G., GORDON, L.M., MARON, J.L., SCHICK, C.T., TABILO, E., ANTAS, P. \& BELOW, T. 1990. Migration routes of new world sanderlings (Calidris alba). The Auk 107:172-180.

MORRISON, R.I.G. 1984. Migration systems of some New World shorebirds. Behav. Mer. Org. 6:123-202.

MORRISON, R.I.G. \& ROSS, R.K. 1989. Atlas of neartic shorebirds on the coast of South America. Canadian Wildlife Service, Ottawa, 325p.

NASCIMENTO, J.L.X. \& LARRAZÁBAL, M.E.L. 2000. Alimentação de aves limícolas em Barra de Cunhaú, Canguaretama, Rio Grande do Norte. Melopsittacus. (3):91-120.

PETRY, M.V., SCHERER, J.F.M. \& SCHERER, A.L. 2012 . Ocorrência, alimentação e impactos antrópicos de aves marinhas nas praias do litoral do Rio Grande do Sul, Sul do Brasil. Rev. Bras. Ornitol. 20:65-70.

POWELL, G.V.N. \& POWELL, A.H. 1986. Reproduction by great white herons Ardea Herodias in Florida Bay as an indicator of habitat quality. Biol. Conser. 36:101-13.

RODRIGUES, A.A.F. 2000. Seasonal abundance of nearctic shorebirds in the Gulf of Maranhão, Brazil. Journal of Field Ornithology 71: 655-675.

SANABRIA, J.A.F. \& BRUSCO, G.M. 2011. Registros relevantes de Chradriiformes em praias do Litoral Norte do Rio Grande do Sul. Rev. Bras. Ornitol. 19(4):529-534.

SCHERER, A.L. \& PETRY, M.V. 2012. Seasonal Variation In Shorebird Abundance In The State of Rio Grande do Sul, Southern Brazil. The Wilson Journal of Ornithology, 124:40-50.

SCHIEFLER, F.A. \& SOARES, M. 1994. Estudo comparativo da avifauna das praias de Navegantes e Laguna, Santa Catarina. Biotemas 7(1-2):31-45.

SICK, H. 1997. Ornitologia brasileira. Editora Nova Fronteira, Rio de Janeiro, 868p.

SUGUIO, K. \& MARTINS, L. 1987. Classificação de costas e evolução geológica das planícies litorâneas quartenárias do sudeste e Sul do Brasil. Simpósio sobre Ecossistema da Costa Sul e Sudeste Brasileira, Síntese dos conhecimentos. ACIESP. 54-I: 1-28.

TELINO-JÚNIOR, W.R., AZEVEDO JÚNIOR, S.M. \& LYRA-NEVES, R.M. 2003. Censo de aves migratórias (Charadriidae, Scolopacidae e Laridae) na Coroa do Avião, Igarassu, Pernambuco, Brasil. Rev. Bras. Zool. 20(3):451-456.

TESSLER, M.G. 1988. Dinâmica sedimentar quartenária no litoral Sul paulista. São Paulo. Tese de doutorado, Instituto de Geologia da Universidade de São Paulo, 276p.

TESSLER, M.G. \& SOUZA, L.A.P. 1998. Dinâmica sedimentary e feições sedimentares na superfície de fundo do sistema Cananéia-Iguape, SP. Bol. Inst. Oceanogr. 46:69-93.

VOOREN, C.M. \& CHIARADIA, A. 1990. Seasonal Abundance and behaviuor of Coastal Birds on Cassino Beach, Brazil. Ornitol. Neotrop. $1: 9-14$.

WARNOCK, N., ELPHICK, C. \& RUBEGA, M.A. 2002. Shorebirds in the Marine Environment. In: Biology of Marine Birds (E. A. Schreiber \& J. Burger, ed.). CRC Press, New York.

ZAR, J.H. 1999. Biostatistical Analysis. 4th ed. Prentice-Hall, NewJersey, $663 \mathrm{p}$. 
Barbieri, E. et al.

Apêndice. Fotos de algumas espécies encontradas durante a realização deste trabalho.
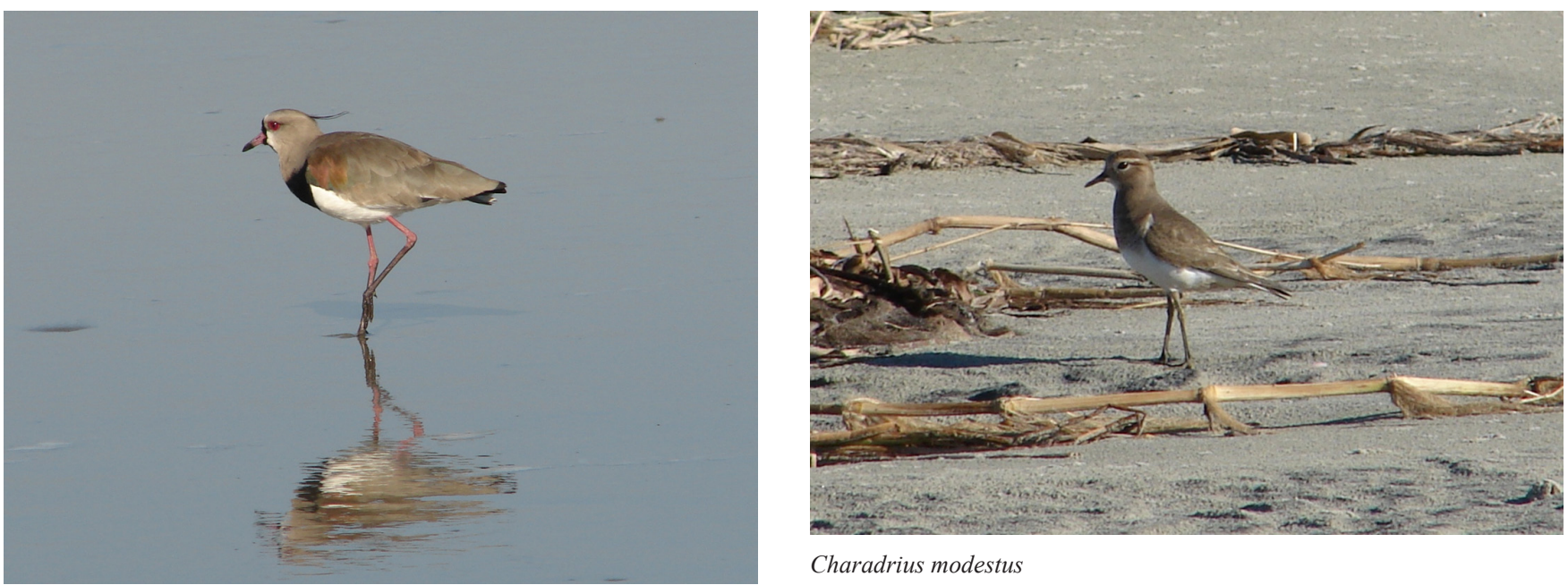

Vanelus chilensis

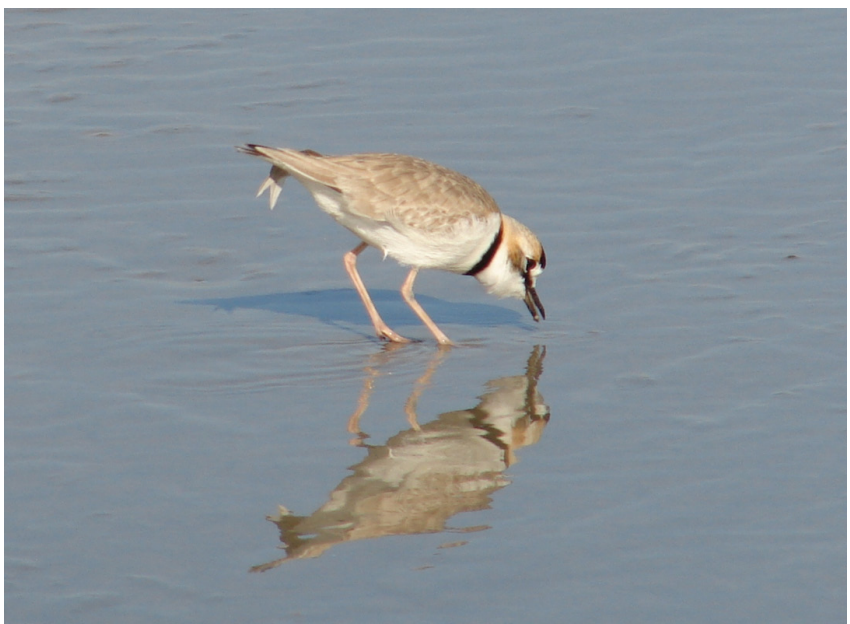

Charadrius collares

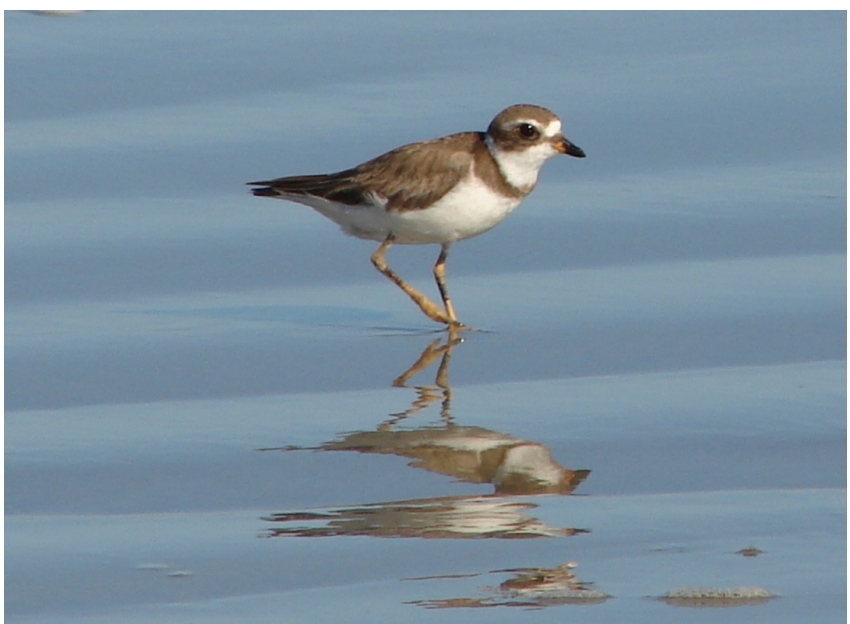

Chradrius semipalmatus

Charadrius modestus

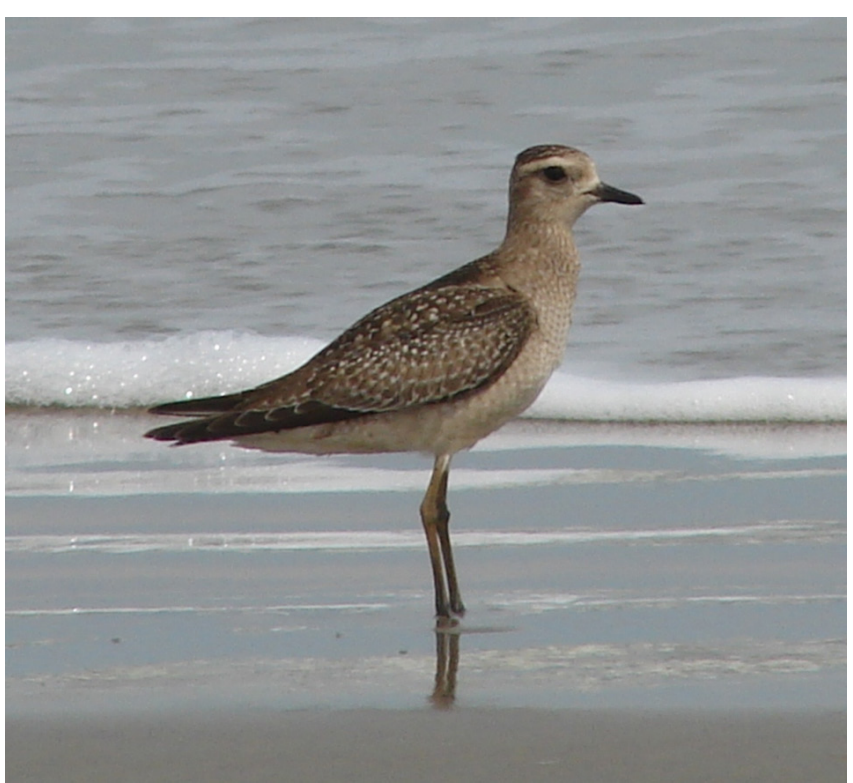

\section{Pluvialis dominica}

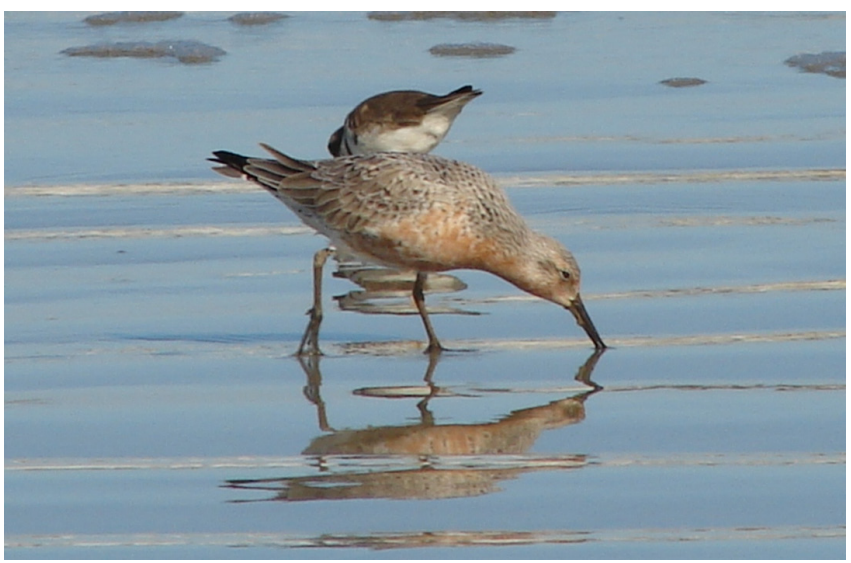

Calidris canutus 


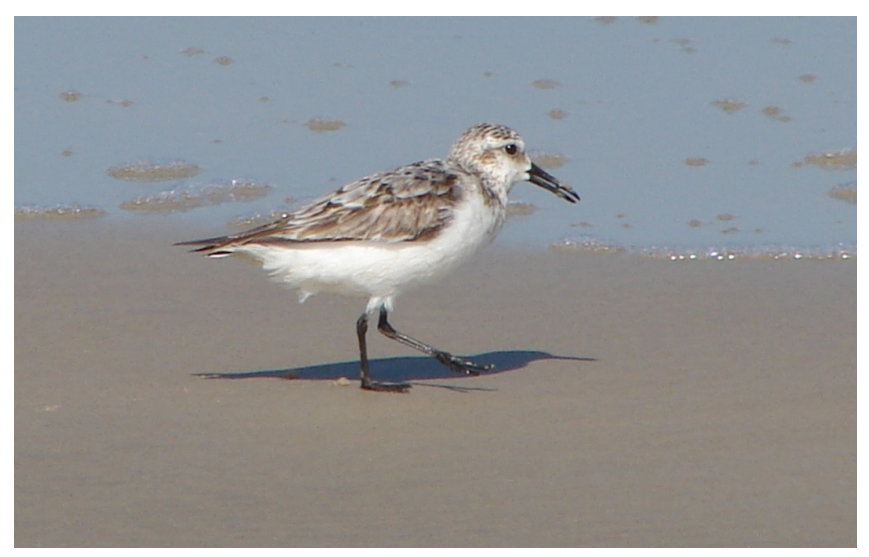

\section{Calidris alba}

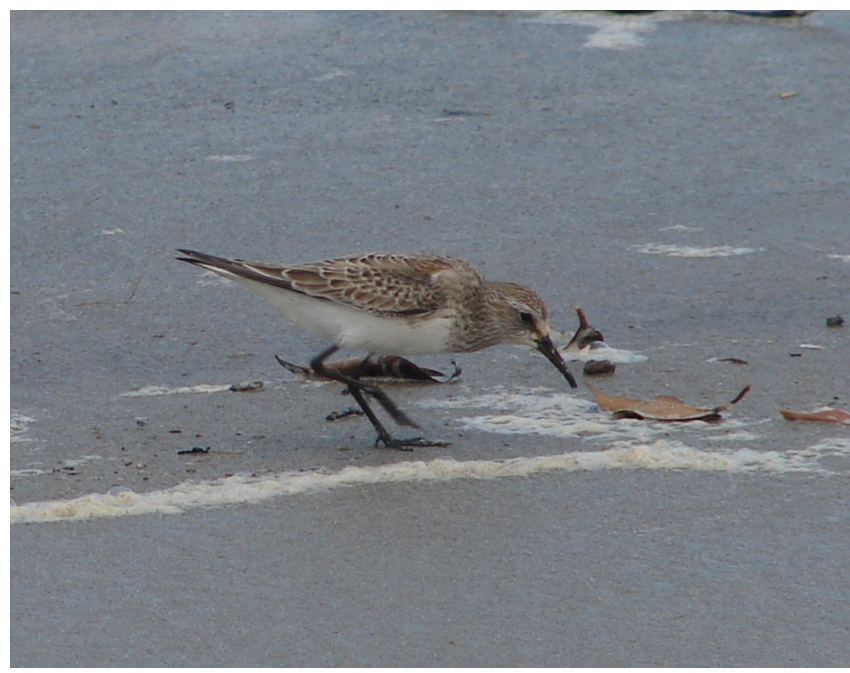

Calidris fuscicolis

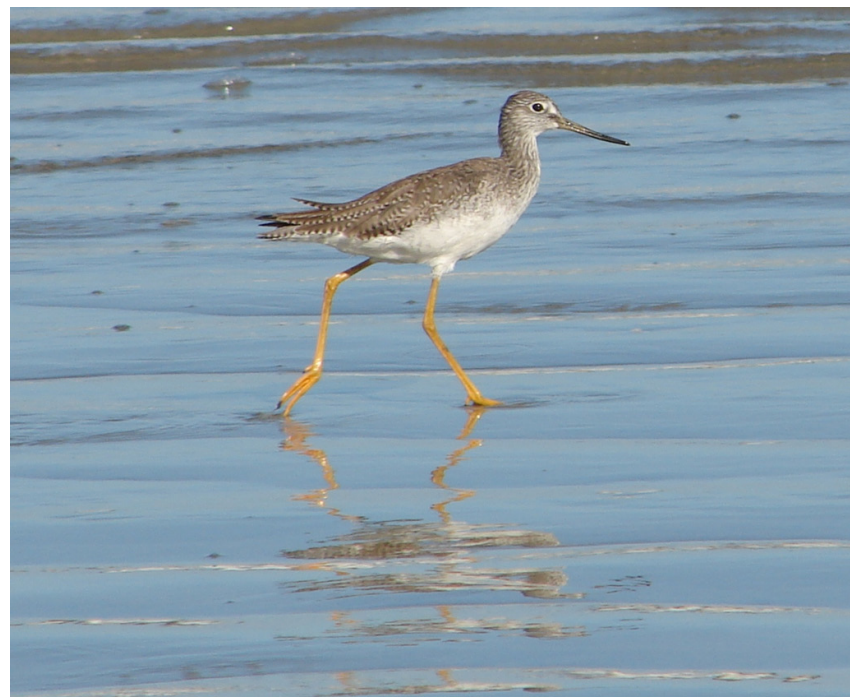

Tringa flavipes

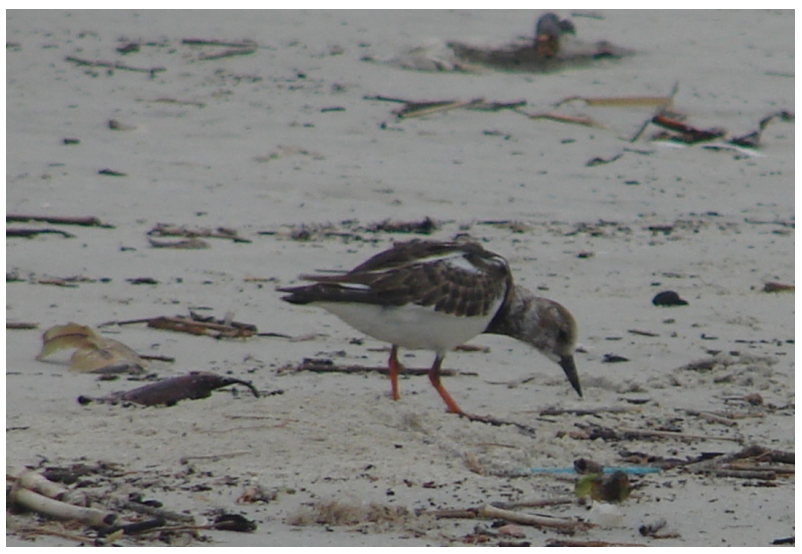

Arenaria interpres

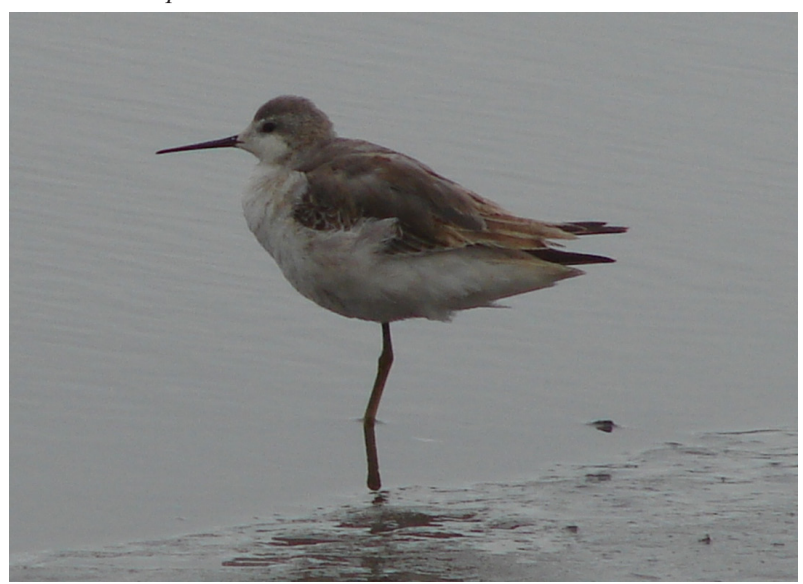

Phalaropus tricolor

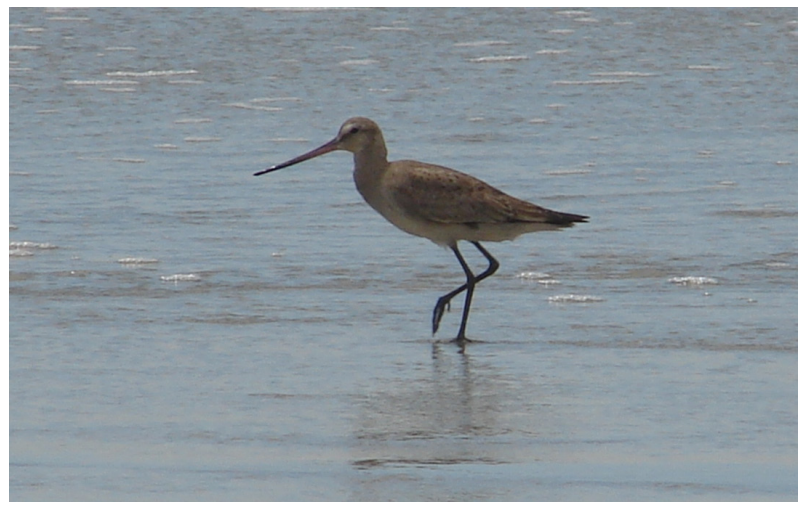

Limosa haemastica

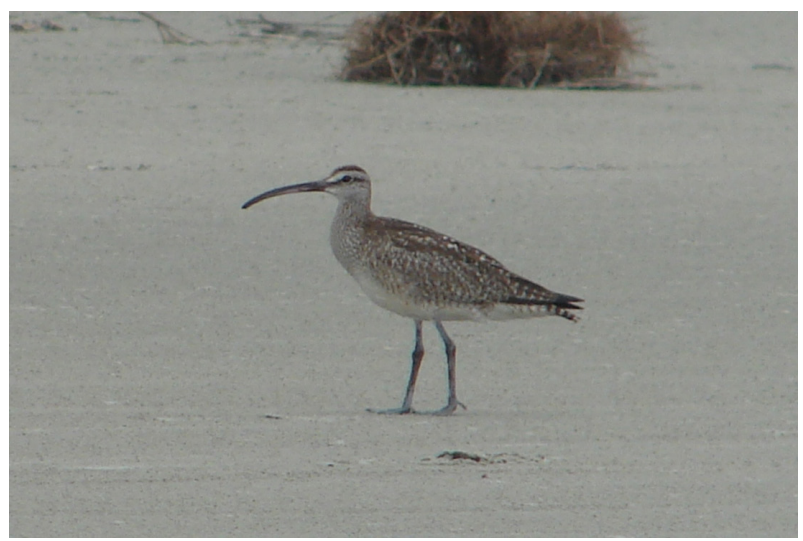

Numenius phaeopus 